Check for updates

Cite this: Phys. Chem. Chem. Phys., 2018, 20, 12260

Received 20th February 2018, Accepted 15th April 2018

DOI: $10.1039 / \mathrm{c} 8 \mathrm{cp} 01148 \mathrm{f}$

rsc.li/pccp

\title{
Surface structure, optoelectronic properties and charge transport in ZnO nanocrystal/MDMO-PPV multilayer films $\dagger$
}

\author{
Qing Lian, ${ }^{a}$ Mu Chen, ${ }^{a}$ Muhamad Z. Mokhtar, ${ }^{a}$ Shanglin Wu, ${ }^{a}$ Mingning Zhu, ${ }^{a}$ \\ Eric Whittaker, ${ }^{\text {b }}$ Paul O'Brien (D) ${ }^{\text {ac }}$ and Brian R. Saunders (D) *a
}

\begin{abstract}
Blends of semiconducting nanocrystals and conjugated polymers continue to attract major research interest because of their potential applications in optoelectronic devices, such as solar cells, photodetectors and light-emitting diodes. In this study we investigate the surface structure, morphological and optoelectronic properties of multilayer films constructed from ZnO nanocrystals (NCs) and poly[2-methoxy-5- $\left(3^{\prime}, 7^{\prime}-\right.$ dimethyloctyloxy)-1,4-phenylenevinylene] (MDMO-PPV). The effects of layer number and $\mathrm{ZnO}$ concentration $\left(C_{\mathrm{ZnO}}\right)$ used on the multilayer film properties are investigated. An optimised solvent blend enabled wellcontrolled layers to be sequentially spin coated and the construction of multilayer films containing six ZnO NC (Z) and MDMO-PPV (M) layers (denoted as $\left.(Z M)_{6}\right)$. Contact angle data showed a strong dependence on $C_{Z n O}$ and indicated distinct differences in the coverage of MDMO-PPV by the ZnO NCs. UV-visible spectroscopy showed that the MDMO-PPV absorption increased linearly with the number of layers in the films and demonstrates highly tuneable light absorption. Photoluminescence spectra showed reversible quenching as well as a surprising red-shift of the MDMO-PPV emission peak. Solar cells were constructed to probe vertical photo-generated charge transport. The measurements showed that $(Z M)_{6}$ devices prepared using $C_{Z n O}=14.0 \mathrm{mg} \mathrm{mL}^{-1}$ had a remarkably high open circuit voltage of $\sim 800 \mathrm{mV}$. The device power conversion efficiency was similar to that of a control bilayer device prepared using a much thicker MDMO-PPV layer. The results of this study provide insight into the structure-optoelectronic property relationships of new semiconducting multilayer films which should also apply to other semiconducting NC/polymer combinations.
\end{abstract}

\section{Introduction}

Hybrid nanocrystal (NC)/polymer composites contain semiconducting inorganic NCs (or quantum dots) dispersed within a conjugated polymer matrix. ${ }^{1-5}$ They continue to attract considerable activity from both the fundamental ${ }^{6-9}$ and practical perspectives. $^{10,11}$ Potential applications for such composites include solar cells, ${ }^{12,13}$ photodetectors ${ }^{14,15}$ or light emitting diodes. ${ }^{16}$ Unfortunately, the intrinsic lack of colloidal stability during composite formation is an obstacle that frustrates efforts to obtain high efficiency semiconducting NC/polymer solar cells. ${ }^{17}$ This instability prevents attainment of a controlled network of connected NCs dispersed throughout the conjugated

\footnotetext{
${ }^{a}$ School of Materials, University of Manchester, MSS Tower, Manchester, M13 9PL, UK. E-mail: Brian.saunders@manchester.ac.uk

${ }^{b}$ Photon Science Institute, University of Manchester, Alan Turing Building, Oxford Road, Manchester, M13 9PL, UK

${ }^{c}$ School of Chemistry, University of Manchester, Manchester, M13 9PL, UK

$\dagger$ Electronic supplementary information (ESI) available. See DOI: 10.1039/c8cp01148f
}

polymer phase. ${ }^{18}$ Very small separations between connected strings of NCs are required to maximise the exciton diffusion yield because the exciton diffusion length for conjugated polymers is typically less than $10 \mathrm{~nm} .{ }^{19}$ The power conversion efficiencies (PCEs) for NC/polymer solar cells remain relatively low compared to comparable technologies such as polymer-fullerene solar cells ${ }^{20}$ despite elegant approaches designed to circumvent the colloidal instability problem. ${ }^{2,17,21}$ Here, we aimed to introduce a degree of tuneable order perpendicular to the film plane within semiconducting NC/polymer composites. Such composites utilised multilayer films with polymer layer thicknesses less than the exciton diffusion length. The surface structures and morphologies of the multilayer films are studied to understand their influence on the optoelectronic properties of the films and photo-generated charge transport in the $z$-direction. A practical question addressed is whether operational solar cells could be achieved using such semiconducting multilayer NC/polymer films.

ZnO NCs were used as the model semiconducting NC system in this study. They can be conveniently prepared using a solvothermal method ${ }^{22}$ or chemical vapor deposition ${ }^{23}$ and have 
been reviewed elsewhere. ${ }^{24,25} \mathrm{ZnO}$ has a large band gap $(\sim 3.2 \mathrm{eV})$, a very high electron mobility and is an electron acceptor. ${ }^{25,26}$ The ZnO NC/polymer solar cells with the highest PCE reported are those in seminal work from the Janssen group. ${ }^{17}$ They used in situ ZnO NC preparation during film formation to bypass colloidal instability obstacles. However, there are two challenges present for in situ NC formation within composite films which are lack of control over NC size and placement. Other approaches that provided structural control within $\mathrm{ZnO} \mathrm{NC}$ /polymer composites include using pre-formed $\mathrm{ZnO}$ nanorods ${ }^{26}$ or porous $\mathrm{ZnO} \mathrm{NC}$ films. ${ }^{27}$ Whilst these approaches may allow well-defined vertical pathways to be established for electron transport, infiltration of the polymer into the spaces can be hindered if the latter are very small. ${ }^{28}$ Here, we aimed to retain NC colloidal stability whilst precisely controlling the location of the NC and polymer components in multilayer films using sequential spin coating.

Whilst ZnO NCs have been studied for decades ${ }^{22,29}$ their use in multilayer composite films has received less attention. Such films have mainly been studied within bespoke tandem and multilayer solar cells ${ }^{30-34}$ with component energy levels carefully selected to maximise the PCE. The approach used in the present study is depicted in Scheme 1. Multilayer films were constructed by sequentially spin coating layers of ZnO NCs (denoted as Z) and poly[2-methoxy-5-( $3^{\prime}, 7^{\prime}$-dimethyloctyloxy)1,4-phenylenevinylene] (MDMO-PPV, denoted as M). MDMOPPV was used at the donor in this study because earlier studies showed the photoluminescence behaviour for ZnO NC/MDMOPPV films to be well controlled by the proportion of each species. ${ }^{29}$ Our multilayer films consisted of one type of polymer donor and NC acceptor with a repeating bilayer (heterojunction) structure. This design simplified the study and enabled a clearer understanding of the structure-optoelectronic properties to be discerned. Multilayer films with up to six $\mathrm{Z}$ and $\mathrm{M}$ layers (i.e., $(\mathrm{ZM})_{6}$ ) were constructed. Our multilayer films were not designed to provide high PCE devices. Rather, we employed solar cell measurements to study the effect of ZnO NC layer thickness on vertical photo-generated charge transport via the short-circuit current density (see later).

The study begins with establishing a solvent-blend which gave colloidally stable $\mathrm{ZnO}$ NC dispersions that did not adversely affect the underlying MDMO-PPV layers when spin coated. Multilayer films are then constructed and characterised using surface profilometry (for layer thickness), SEM, AFM as well as contact angle measurements. The optical properties of the films are investigated using UV-visible and photoluminescence (PL) spectroscopy. Solar cell data are then considered and the effect of $\mathrm{ZnO}$ film layer thickness studied. The latter data provide evidence for vertical charge transport pathways through the multilayer films. Finally, all of the results are considered to propose structural models of the multilayer films. The sequential spin coating method established here for ZnO NC/MDMO-PPV multilayer films provides optoelectronic properties that are tuneable using the number of layers and NC concentration. Our approach and the results obtained should be applicable to a range of other semiconducting NC/conjugated polymer films or devices.

\section{Experimental details}

\section{Materials}

Zinc acetate dihydrate $\left(\mathrm{Zn}(\mathrm{Ac})_{2} \cdot 2 \mathrm{H}_{2} \mathrm{O}, 98 \%\right), \mathrm{KOH}(85 \%)$, methanol (MeOH, 99.8\%), butanol (BuOH, >99\%), $\mathrm{CHCl}_{3}$ (99.8\%), chlorobenzene (CBZ, anhydrous, 99.8\%) and MDMO$\operatorname{PPV}\left(M_{\mathrm{n}} \sim 120000 \mathrm{~g} \mathrm{~mol}^{-1}\right)$ were purchased from Sigma-Aldrich. 1-Propylamine (1-PA, >99\%) and isopropanol (IPA, anhydrous, 99.5\%) were purchased from Alfa Aesar. All of the above materials were used as received. Ultrahigh purity water (distilled and deionised) was used in all experiments.

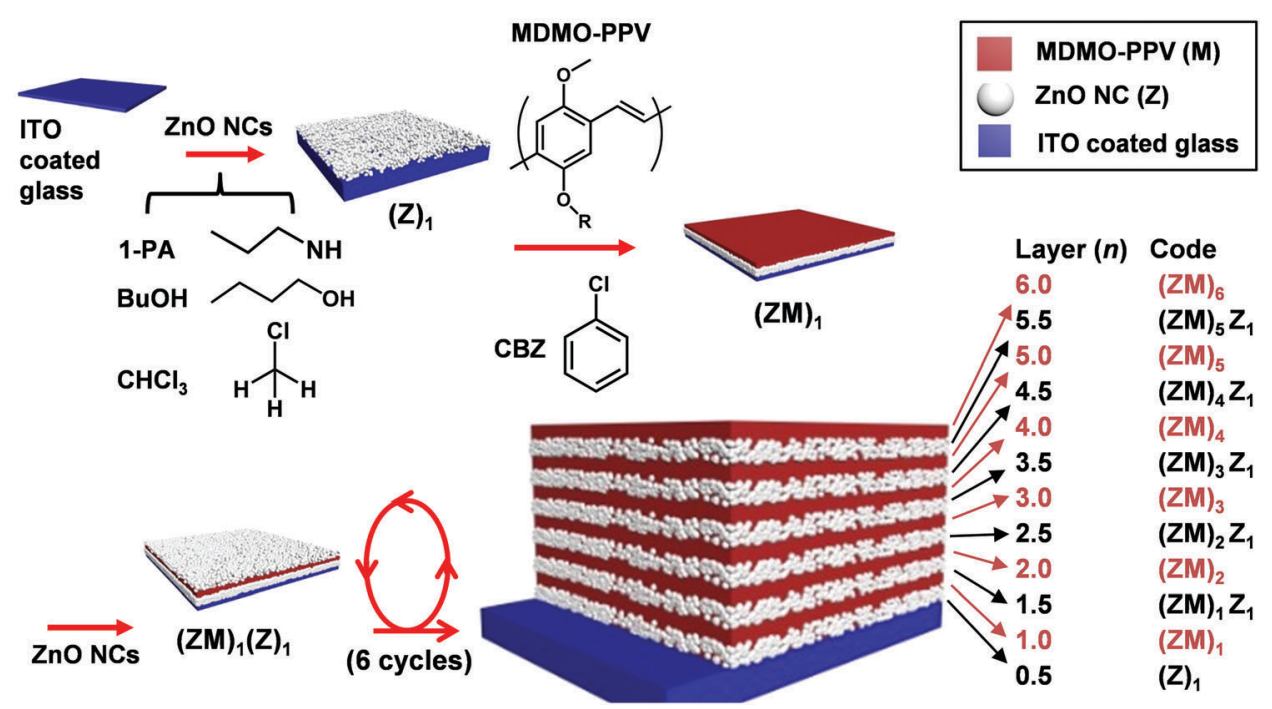

Scheme 1 Depiction of preparation of ZnO NC/MDMO-PPV multilayer films. Each layer was formed by spin coating a ZnO NC dispersion or a MDMOPPV solution. $(Z M)_{n}$ and $(Z M)_{n}(Z)_{1}$ (where $n=1$ to 6 ) correspond to multilayer films that contain MDMO-PPV or ZnO NCs as the top layer, respectively. The parameter $n$ is the number of bilayers. 


\section{ZnO nanocrystals synthesis}

ZnO NCs were synthesised following the method reported previously. ${ }^{29}$ Briefly, $\mathrm{Zn}(\mathrm{Ac})_{2} \cdot 2 \mathrm{H}_{2} \mathrm{O}(2.95 \mathrm{~g}, 13.4 \mathrm{mmol})$ was dissolved in $\mathrm{MeOH}(125 \mathrm{~mL})$ and heated to $60{ }^{\circ} \mathrm{C}$. Then a solution of $\mathrm{KOH}(1.51 \mathrm{~g}, 18.6 \mathrm{mmol})$ in $\mathrm{MeOH}(65 \mathrm{~mL})$ was slowly added over $10 \mathrm{~min}$ with vigorous stirring. After $5 \mathrm{~min}$ the solution became translucent and the stirring was continued for 150 min. Finally, the ZnO NCs were washed twice with $\mathrm{MeOH}$, collected by centrifuge and re-suspended in hexane. The purified $\mathrm{NC}$ dispersion was stored at $-18{ }^{\circ} \mathrm{C}$ until use.

\section{Multilayer film preparation}

$\mathrm{A} \mathrm{BuOH} / \mathrm{CHCl}_{3} / 1$-PA solvent blend (volume ratio of $5: 1: 1$ ) was used to disperse the ZnO NCs. The 1-PA acted as a ligand. ${ }^{27,29}$ The ZnO NC dispersion was filtered through a 0.01 um PTFE syringe filter before use. The $\mathrm{ZnO} \mathrm{NC}$ concentrations $\left(C_{\mathrm{ZnO}}\right)$ used in this study were in the range of 5.0 to $28.0 \mathrm{mg} \mathrm{mL} \mathrm{mL}^{-1}$. Spin-coating was performed using pre-cleaned glass substrates $\left(\sim 2.0 \times 1.5 \mathrm{~cm}^{2}\right)$ or ITO-coated glass substrates $\left(20 \Omega \mathrm{sq}^{-1}\right)$. The latter were cleaned by sonication in a $1 \%$ Hellmanex solution, rinsed with IPA, water and then dried. Spin-coating was conducted using a Laurell, Model WS-650Mz-23NPP spincoater. First, a ZnO NC layer was spin-coated using NCs dispersed in the solvent blend $(50 \mu \mathrm{L})$ onto the ITO glass (2000 rpm, $1.0 \mathrm{~min})$. A MDMO-PPV solution in CBZ $(50 \mu \mathrm{L}$, $3.0 \mathrm{mg} \mathrm{mL}^{-1}$ ) was then spin coated on top of the $\mathrm{ZnO}$ NC layer (2000 rpm, $1.0 \mathrm{~min}$ ) to give a $(\mathrm{ZM})_{1}$ film (Scheme 1). These steps were repeated to construct multilayer films ((denoted $\mathrm{ZM})_{n}$, $n \leq 6)$. All films were stored in a vacuum chamber or a nitrogen filled glove box.

\section{Solar cell fabrication}

The patterned ITO glass (Ossila Ltd UK) was ultrasonically cleaned for $30 \mathrm{~min}$ in $1 \%$ Hellmanex III solution, IPA and then aqueous $\mathrm{NaOH}$ solution $(2.5 \mathrm{M})$. Finally, the patterned ITO glass was extensively washed with water and dried under a $\mathrm{N}_{2}$ gas stream and annealed on a hotplate as described below. The process of multilayer $(\mathrm{ZM})_{6}$ film preparation used was the same as that described above. A PEDOT:PSS solution $(100 \mu \mathrm{L}, 1.3 \mathrm{wt} \%$ in water) was spin coated on top of the final MDMO-PPV layer at $4000 \mathrm{rpm}$ at $90{ }^{\circ} \mathrm{C}$. The film was then annealed at $100{ }^{\circ} \mathrm{C}$ for $10 \mathrm{~min}$ on a hotplate. The thickness of PEDOT:PSS layer was $\sim 100 \mathrm{~nm}$. An Au layer $(80 \mathrm{~nm})$ was deposited on top of the PEDOT:PSS layer to complete the device.

A bilayer control device was prepared with $1 \mathrm{ZnO}$ and

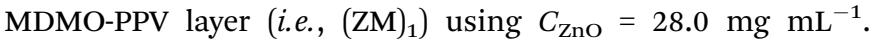
MDMO-PPV solution in CBZ $\left(6.0 \mathrm{mg} \mathrm{mL}^{-1}\right)$ was spin coated onto the ZnO layer at $2000 \mathrm{rpm}$. The thickness of the MDMOPPV layer was $51 \mathrm{~nm}$. PEDOT:PSS $(100 \mu \mathrm{L})$ was then spin coated on top of the MDMO-PPV layer and annealed and Au deposited as described above.

\section{Physical measurements}

Dynamic light scattering (DLS) was conducted using a $50 \mathrm{~mW}$ $\mathrm{He} / \mathrm{Ne}$ laser operated at $633 \mathrm{~nm}$ with a standard avalanche photodiode and $90^{\circ}$ detection optics connected to a Malvern Zetasizer Nano ZS90 autocorrelator. SEM was performed using FEI Quanta 650 FEG-SEM and FEI Magellan 400 XHR FEG-SEM instrument. The samples were coated with Pt. TEM data were obtained using an FEI Tecnai F30 FEG-AEM instrument. The samples were deposited onto holy carbon film from Agar Scientific. Atomic force microscopy (AFM) images were obtained with an Asylum Research MFP-3D operating in AC ("tapping") mode. Imaging was performed using an Olympus high aspect ratio etched silicon probes (OTESPA) with a nominal spring constant of $42 \mathrm{~N} \mathrm{~m}^{-1}$ (Bruker AXS S.A.S., France). The cantilever oscillation frequency varied between 300 and $350 \mathrm{kHz}$ and was determined by the auto-tune facility of the Asylum software, as was the drive amplitude. The thickness of the films was measured using a DektakXT profilometer. Contact angle measurements were performed using water and a Krüss Drop Shape Analysis (DSA100) instrument. All contact angle measurements were performed at room temperature. UV-visible spectra were obtained by using a Hitachi U-1800 spectrophotometer. PL spectra were measured using a double monochromator FLS980 instrument (Edinburgh Instruments, UK), which was equipped with a xenon lamp and detector (R928.0P, Hamamatsu). The excitation wavelength was $505 \mathrm{~nm}$.

\section{Device measurements}

The current density-voltage $(J-V)$ characteristics were measured using a Keithley 2420 Sourcemeter and $100 \mathrm{~mW} \mathrm{~cm}^{-2}$ illumination (AM 1.5G) together with a calibrated NREL certified Oriel Si-reference cell. An Oriel SOL3A solar simulator was used for these experiments. The active area of the devices was defined using a square aperture within a mask and fixed at $0.025 \mathrm{~cm}^{2}$. The scan rate was $100 \mathrm{mV} \mathrm{s}^{-1}$.

\section{Results and discussion}

\section{Multi-layer film morphology and surface hydrophilicity/ hydrophobicity switching}

It was important to use a solvent blend that provided colloidally stable ZnO NCs to enable deposition of well-controlled multilayer films by spin coating. A further goal for the solvent blend was that it should not dissolve the underlying MDMO-PPV layer. A preliminary study was conducted using a range of solvents. Finally, a $\mathrm{BuOH}, \mathrm{CHCl}_{3}$ and 1-PA solvent blend (volume ratio of $5: 1: 1)$ was selected for dispersing the ZnO NCs. The solvent blend maintained NC colloidal stability and minimised MDMO-PPV dissolution. TEM images obtained for the ZnO NCs (see Fig. S1(a), ESI $\dagger$ ) gave a number-average diameter $\left(d_{\text {TEM }}\right)$ of $4.1 \pm 0.4 \mathrm{~nm}$. A UV-visible spectrum measured for the dispersed NCs (see Fig. S1(b), ESI $\dagger$ ) gave a wavelength at which the absorption is half that of the excitonic peak $\left(\lambda_{1 / 2}\right)$ of $360 \mathrm{~nm}$. This value enabled the NC diameter to be calculated as $4.9 \mathrm{~nm}$ following Meulenkamp's method. ${ }^{22}$ DLS data were also obtained (see Fig. S1(c), ESI $\dagger$ ) which showed a monomodal size distribution and gave a mean (z-average) diameter $\left(d_{z}\right)$ of $13 \mathrm{~nm}$. The relatively large $d_{z}$ value is due to 1-PA adsorbed to the ZnO NCs and the 
disproportionately strong scattering of light by larger particles that is a characteristic of DLS. ${ }^{35}$

Multilayer films were constructed using sequential spin coating of ZnO NC and MDMO-PPV solutions (Scheme 1). The first layer deposited was $\mathrm{ZnO}$ NCs (i.e., $\left.(\mathrm{Z})_{1}\right)$. Then an MDMOPPV layer was spin coated on top of the $\mathrm{ZnO} \mathrm{NC}$ layer to give a bilayer film (i.e., $\left.(\mathrm{ZM})_{1}\right)$. The process was repeated to build up multilayer films $\left((\mathrm{ZM})_{n}\right)$. CBZ was used as the solvent for MDMO-PPV because it did not re-disperse the underlying $\mathrm{ZnO}$ NC layer during spin coating of the MDMO-PPV layer. The effects of $C_{\mathrm{ZnO}}\left(=5.0,9.0\right.$ and $\left.28.0 \mathrm{mg} \mathrm{mL}^{-1}\right)$ and numbers of bilayers $(n)$ on the overall thickness of the multilayer films was studied (see Fig. 1(a)). The multilayer films prepared using all three $C_{\mathrm{Zno}}$ values exhibited a linear increase of thickness with increasing $n$. However, the multilayer films prepared using $C_{\mathrm{Zno}}=28.0 \mathrm{mg} \mathrm{mL}{ }^{-1}$ showed a step sequence. This trend is because the $\mathrm{ZnO}$ NC layers were much thicker than the MDMOPPV layers for this film (discussed below).

The ZnO NC or MDMO-PPV layer thickness $\left(t_{\mathrm{L}}\right)$ was calculated from the difference of the overall thicknesses of a given layer and that of the preceding layer (see Fig. 1(b)). These data show that the $t_{\mathrm{L}}$ values for the $\mathrm{ZnO} \mathrm{NC}$ films approach those for the MDMOPPV layers as $C_{\mathrm{ZnO}}$ decreases. The average MDMO-PPV $t_{\mathrm{L}}$ value calculated from the data shown in Fig. 1(b) are plotted in Fig. 1(c) for each $C_{\mathrm{ZnO}}$ used. Clearly, the average MDMO-PPV layer thickness was independent of $C_{\mathrm{ZnO}}$. The average thickness of all of the MDMO-PPV layers (i.e., all the red data points in Fig. 1(b)) was $6.0 \pm 1.4 \mathrm{~nm}$. For comparison, the thickness of a single film of MDMO-PPV spin coated on ITO glass was measured as $10 \pm 0.4 \mathrm{~nm}$. This difference can be explained by some of the MDMO-PPV infiltrating the underlying ZnO NC layers and/or being removed during spin coating. The diameter of a collapsed spherical MDMO-PPV globule with a molecular weight of $120000 \mathrm{~g} \mathrm{~mol}^{-1}$ can be shown to be $\sim 8 \mathrm{~nm}$ assuming a density of $0.91 \mathrm{~g} \mathrm{~mL}^{-1} \cdot{ }^{36}$ Hence, the MDMO-PPV layers can be thought of as monolayers of MDMO-PPV globules.

We next consider the $\mathrm{ZnO} \mathrm{NC}$ layers. The average $\mathrm{ZnO} \mathrm{NC}$ layer thickness (i.e., for $\left.(\mathrm{ZM})_{n}(\mathrm{Z})_{1}\right)$ was $5.1 \pm 1.2 \mathrm{~nm}$ for the multilayer films prepared using $C_{\mathrm{ZnO}}=5 \mathrm{mg} \mathrm{mL}^{-1}$ (Fig. 1(b), top). However, the thickness of the $\mathrm{ZnO} \mathrm{NC}$ layers were larger than that for the MDMO-PPV layers (i.e., $(\mathrm{ZM})_{n}$ ) when the $C_{\mathrm{ZnO}}$ value increased to 9.0 and $28.0 \mathrm{mg} \mathrm{mL}^{-1}$ and "zig-zag" trends were apparent (Fig. 1(b) middle and bottom). The average $\mathrm{ZnO}$ NC layer thickness calculated for each of the three multilayer films (from the blue data points in Fig. 1(b)) increased linearly with $C_{\mathrm{Zno}}$ (see Fig. 1(c)). It is interesting to compare the latter values with the thicknesses of single $\mathrm{ZnO} \mathrm{NC}$ films of (i.e., $\left.(\mathrm{Z})_{1}\right)$ deposited on ITO using the same $C_{\mathrm{Zno}}$ values (see Fig. 1(c)). (Additional data for $(Z)_{1}$ deposited on ITO are shown in Fig. S2, $\mathrm{ESI} \dagger$ ). These data show that there is no significant difference between the layer thicknesses for ZnO NC layers deposited on ITO and MDMO-PPV layers in the multilayer films. Thus, the

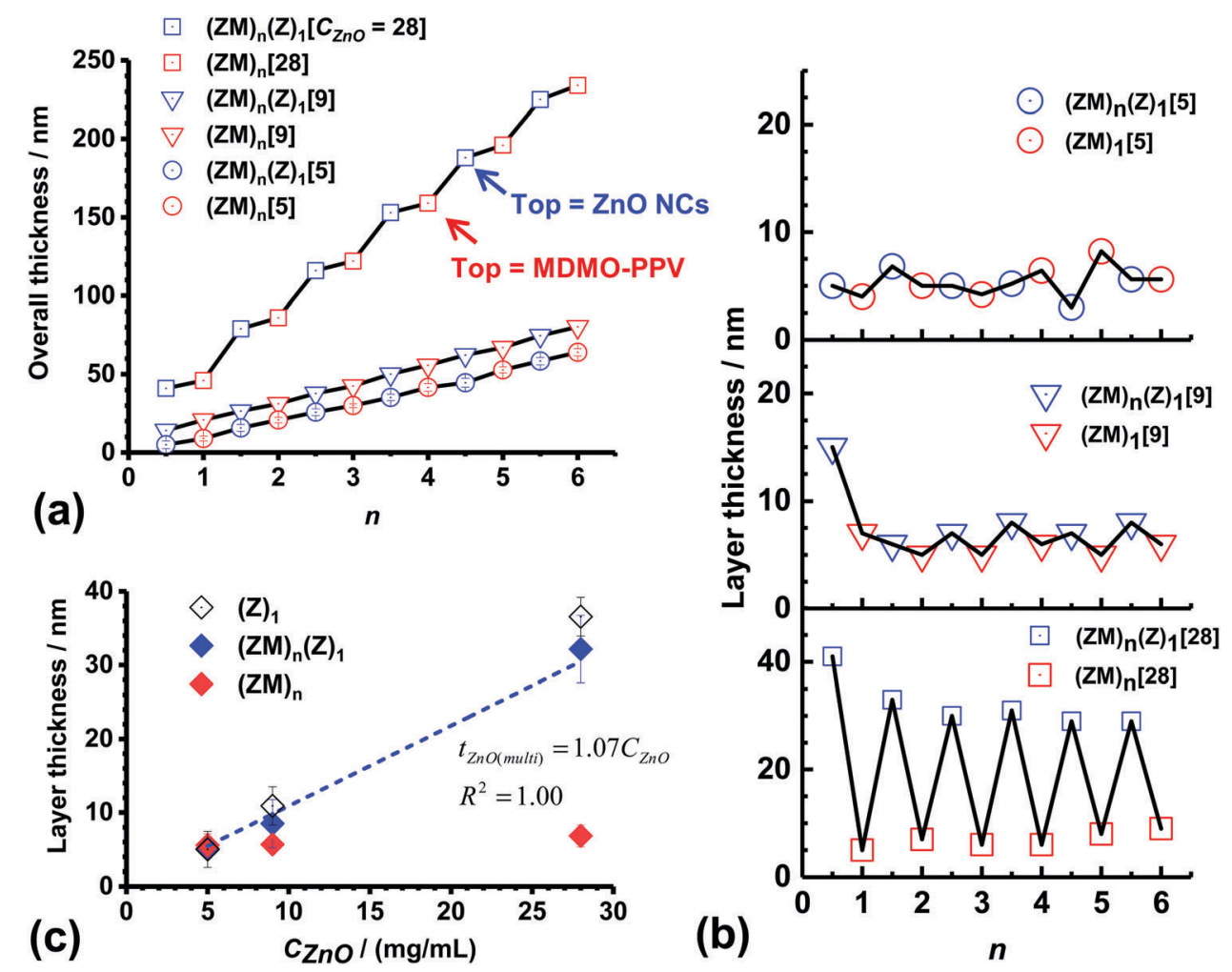

Fig. 1 (a) Variation of overall thickness of ZnO NC/MDMO-PPV multilayer films prepared using $C_{\mathrm{ZnO}}=5.0,9.0$ and $28.0 \mathrm{mg} \mathrm{mL}-1$ with number of bilayers $(n)$. The top layer of the $(Z M)_{n}$ films was MDMO-PPV. The top layer of the $(Z M)_{n}(Z)_{1}$ films was $Z n O$. The numbers in square brackets are $C_{Z n O}$. (b) Calculated layer thickness ( $=t_{\mathrm{L}(n)}-t_{\mathrm{L}(n-0.5)}$, where $n=0.5$ to 6.0 ) for the three multilayer films. (c) Variation of the average layer thickness with $C_{Z n O}$. Data are also shown for one ZnO NC layer (i.e., $\left.(\mathrm{Z})_{1}\right)$ deposited on ITO for comparison and are taken from Fig. S2 (ESI $\dagger$ ). 
ZnO NCs did not become significantly submerged in the underlying MDMO-PPV layers. The ZnO layers within the multilayer films prepared using $C_{\mathrm{ZnO}}=5.0,9.0$ and $28.0 \mathrm{mg} \mathrm{mL}^{-1}$ can be approximated as $\sim 1,2$ and $8 \mathrm{ZnO}$ NC monolayers, respectively, from the $d_{\text {TEM }}$ value $(4.1 \mathrm{~nm})$ and the average ZnO NC layer thicknesses of 5.1, 8.5 and $32.2 \mathrm{~nm}$ from Fig. 1(c).

The morphologies for the multilayer films prepared using $C_{\mathrm{ZnO}}=28.0 \mathrm{mg} \mathrm{mL} \mathrm{mL}^{-1}$ were investigated using SEM and AFM. Selected images measured for the $(\mathrm{ZM})_{3}(\mathrm{Z})_{1},(\mathrm{ZM})_{4}$ and $(\mathrm{ZM})_{4}(\mathrm{Z})_{1}$ films are shown in Fig. 2. (SEM and AFM images were measured for the other layers and are shown in Fig. S3 and S4, respectively, ESI $\dagger$ ). The SEM images (Fig. 2(a)-(c)) show that the films that had $\mathrm{ZnO}$ NCs as the top layer $\left(\right.$ i.e., $\left((\mathrm{ZM})_{3}(\mathrm{Z})_{1}\right.$ and $\left.(\mathrm{ZM})_{4}(\mathrm{Z})_{1}\right)$ had a polycrystalline appearance and many very small troughs (diameter $<10 \mathrm{~nm}$ ) were present. These troughs are highlighted with arrows. The SEM image measured for the $(\mathrm{ZM})_{4}$ film (MDMO-PPV top layer, Fig. 2(b)) had larger troughs with diameters of 10-20 nm. The AFM images recorded for these films (Fig. 2(d)-(f)) showed similar features to those apparent in the respective SEM images. The line profile data showed that the roughness for the $(\mathrm{ZM})_{4}$ film (RMS roughness $=1.2 \mathrm{~nm}$ ) was much less than those for the $(\mathrm{ZM})_{3}(\mathrm{Z})_{1}$ film (roughness $=2.6 \mathrm{~nm}$ ) and
$\left.(\mathrm{ZM})_{4}(\mathrm{Z})_{1}\right)$ film (roughness $=2.2 \mathrm{~nm}$ ). (This trend is also apparent from the AFM images and line profiles measured for the other $(\mathrm{ZM})_{n}$ and $(\mathrm{ZM})_{n} \mathrm{Z}_{1}$ multilayer films - see Fig. S4, ESI $\left.\dagger\right)$. Hence, the $\mathrm{ZnO}$ NC layers $\left.\left((\mathrm{ZM})_{n}(\mathrm{Z})_{1}\right)\right)$ had a greater roughness than the MDMO-PPV $\left((\mathrm{ZM})_{n}\right.$ layers). This is because the former were composed of non-deformable NCs. The subsequent MDMO-PPV layer (for $\left.(\mathrm{ZM})_{n}\right)$ (mostly) filled in the smaller troughs present in the preceding $\mathrm{ZnO} \mathrm{NC}$ layer. However, some larger diameter troughs remained that were less deep as judged by the AFM line profile data shown in Fig. 2 and Fig. S4 (ESI $\dagger$ ). These features were covered by the next ZnO NC layer, which is why the morphologies repeated as $n$ increased. There was no memory of the preceding $(\mathrm{ZM})_{n-1}$ or $(\mathrm{ZM})_{n-1}(\mathrm{Z})_{1}$ layer morphology by the next, respective, $(\mathrm{ZM})_{n}$ or $(\mathrm{ZM})_{n}(\mathrm{Z})_{1}$ layer. Thus, the surface morphologies for these multilayer films were "reset" after each bilayer cycle.

The hydrophobic and hydrophilic properties of the multilayer film surfaces were investigated using contact angle (CA) measurements. The CA's for MDMO-PPV (i.e., (M) $)_{1}$ ) and $\mathrm{ZnO}$ $\left((\mathrm{Z})_{1}\right)$ deposited on ITO were measured as $95.7^{\circ}$ and $33.2^{\circ}$, respectively. The former value agrees closely with the CA reported for MDMO-PPV. ${ }^{37,38}$ The CA for $\mathrm{ZnO}$ has been reported as $10^{\circ}$ after exposure to UV light. ${ }^{39,40}$ This effect is termed
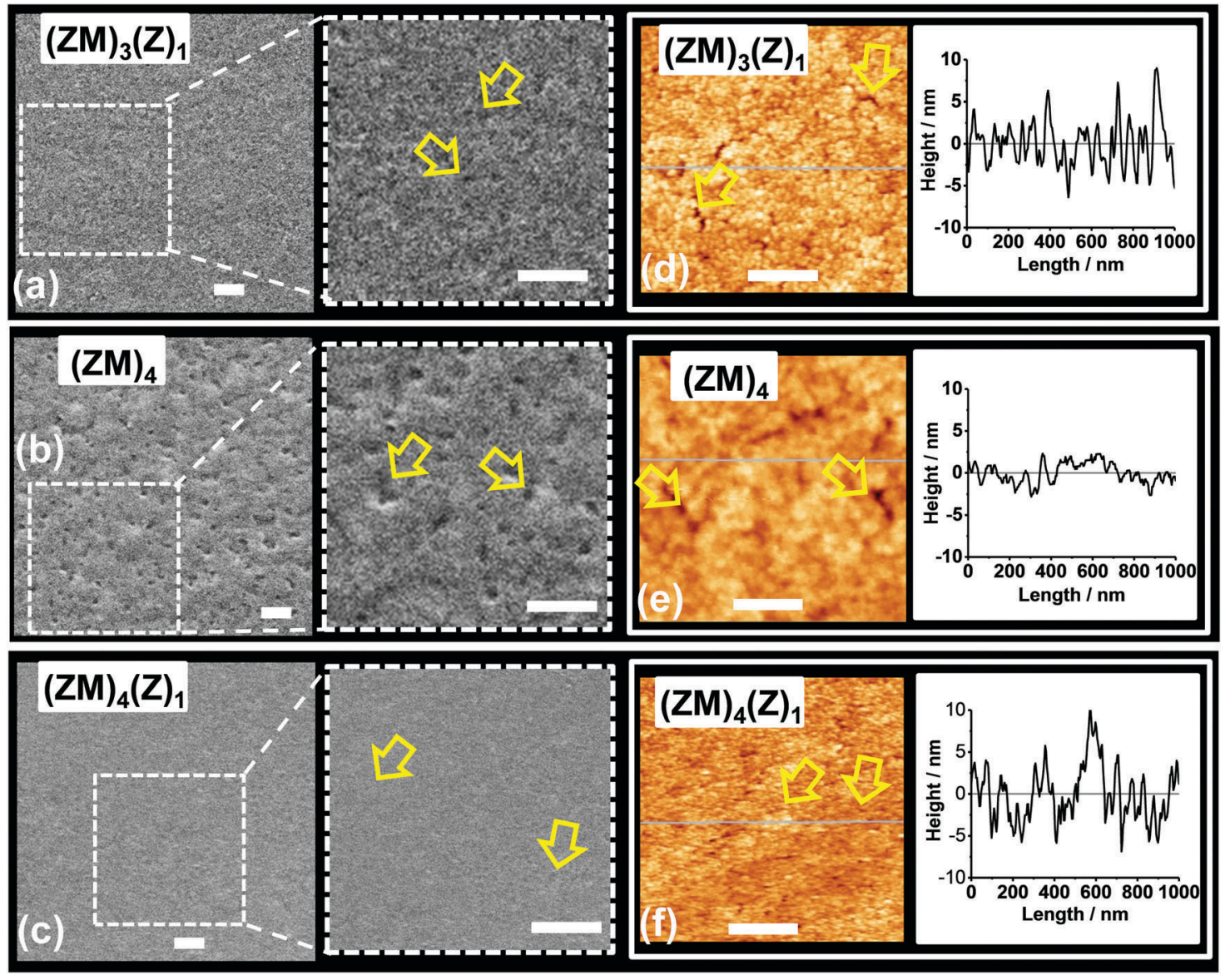

Fig. 2 SEM images for (a) top ZnO NC layer in $(Z M)_{3}(Z)_{1}$ (b) top MDMO-PPV layer in $(Z M)_{4}$ and (c) top $Z n O ~ N C$ layer in $(Z M)_{4}(Z)_{1}$. These films were prepared using $C_{Z n O}=28.0 \mathrm{mg} \mathrm{mL}^{-1}$. The yellow arrows highlight troughs, which had a larger diameter for the $(Z M)_{4}$ films. AFM images and surface profiles were also measured for these films (labelled) and are shown in (d-f). Scale bars: $100 \mathrm{~nm}$. SEM and AFM for other films are shown in Fig. S3 and S4 $(\mathrm{ESI})$, respectively. 

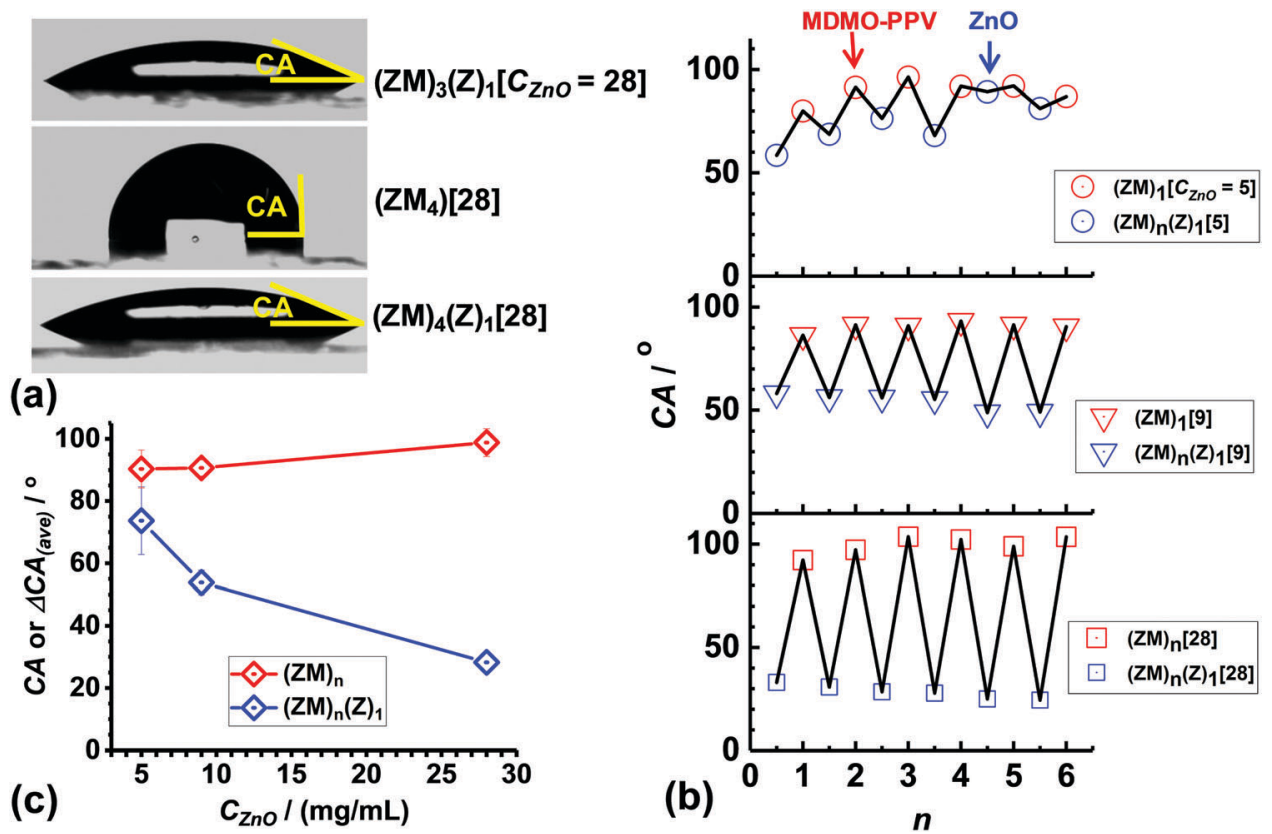

Fig. 3 (a) Images obtained of water droplets on multilayer films prepared using $C_{\mathrm{ZnO}}=28.0 \mathrm{mg} \mathrm{mL}^{-1}$. (b) Contact angles measured for films prepared using $C_{Z n O}=5.0 \mathrm{mg} \mathrm{mL}^{-1}$ (top), $9.0 \mathrm{mg} \mathrm{mL}^{-1}$ (middle) and $28.0 \mathrm{mg} \mathrm{mL}^{-1}$ (bottom). (c) Average contact angles for the MDMO-PPV top layer (i.e., (ZM) $)$ and $\mathrm{ZnO} \mathrm{NC}$ layers (i.e., $\left.(\mathrm{ZM})_{n}(\mathrm{Z})_{1}\right)$ films obtained from the data shown in (b).

photo-induced surface wettability and originates from coordination of $\mathrm{H}_{2} \mathrm{O}$ to $\mathrm{O}_{2}$ vacancy sites. ${ }^{39}$ Fig. 3(a) shows images of water droplets recorded on several of the multilayer films. Clearly, the droplets spread on the top $\mathrm{ZnO}$ layer for $(\mathrm{ZM})_{3}(\mathrm{Z})_{1}$ and $(\mathrm{ZM})_{4}(\mathrm{Z})_{1}$. However, the droplets tended de-wet the top MDMO-PPV layer (for $(\mathrm{ZM})_{4}$ ). These data show that the $\mathrm{ZnO} \mathrm{NC}$ and MDMO-PPV layers are hydrophilic and hydrophobic, respectively.

The CA values measured for each of the layers of the three ZnO NC/MDMO-PPV multilayer films are shown in Fig. 3(b). The data exhibited a "zig-zag" pattern for all of the films which demonstrates that a surface hydrophilicity/hydrophobicity change (switching) occurred with the deposition of each layer. The reversibility of the CA values was reasonably good for the films prepared using $C_{\mathrm{ZnO}}=9.0$ and $28.0 \mathrm{mg} \mathrm{mL}^{-1}$. The data show that for these two multilayer films the surfaces were hydrophilic and hydrophobic for the $(\mathrm{ZM})_{n}(\mathrm{Z})_{1}$ and $(\mathrm{ZM})_{n}$ layers, respectively. The data for the film prepared using $C_{\mathrm{ZnO}}=5.0 \mathrm{mg} \mathrm{mL}^{-1}$ (Fig. 3(b), top) showed a different behavior whereby the CA for the ZnO NC layers increased as $n$ increased and approached the values for MDMO-PPV layers. It follows that when the ZnO NCs were deposited for this film the $(\mathrm{ZM})_{n}(\mathrm{Z})_{1}$ layers had similar hydrophobicity to the underlying $(\mathrm{ZM})_{n}$ layer. This is suggestive of incomplete coverage of the MDMO-PPV layers by the ZnO NCs when $C_{\mathrm{ZnO}}=5.0 \mathrm{mg} \mathrm{mL}^{-1}$. The average values of the CAs shown in Fig. 3(b) are plotted as a function of $C_{\mathrm{Zno}}$ in Fig. 3(c). The average CA values for the $(\mathrm{ZM})_{n}$ layers was independent of $C_{\mathrm{Zno}}$. In contrast the average $\mathrm{CA}$ values for the $(\mathrm{ZM})_{n}(\mathrm{Z})_{1}$ layers decreased with increasing $C_{\mathrm{Zno}}$. It follows that the effectiveness of $\mathrm{ZnO}$ NC coverage of the underlying MDMO-PPV layers increased with increasing $C_{\mathrm{ZnO}}$.

\section{Optical properties of multilayer films}

UV-visible spectra were measured for the ZnO NC/MDMO-PPV multilayer films. The spectra measured for the films prepared using $C_{\mathrm{ZnO}}=28.0 \mathrm{mg} \mathrm{mL}^{-1}$ are shown in Fig. 4(a). (The spectra obtained for the films prepared using $C_{\mathrm{ZnO}}=5.0$ and $9.0 \mathrm{mg} \mathrm{mL}^{-1}$ are shown in Fig. S5, ESI $\dagger$ ). The spectra show an absorption maximum at $505 \mathrm{~nm}$ which is due to MDMO-PPV. ${ }^{29}$ The ZnO NC layers did not strongly contribute to the spectra because $\mathrm{ZnO}$ does not absorb above $400 \mathrm{~nm}$ (Fig. S1(b), ESI $\dagger$ ). The variation of the maximum absorbance with $n$ for the three multilayer films is shown in Fig. $4(\mathrm{~b})$. The film prepared using $C_{\mathrm{ZnO}}=5 \mathrm{mg} \mathrm{mL}^{-1}$ (Fig. 4(b), top) exhibited a step-like sequence. The film absorbance measured for each $\mathrm{ZnO} \mathrm{NC}$ top layer (blue data points) was less than that for the preceding MDMO-PPV top layer (red data points). We conclude from this result that some of the MDMO-PPV was removed as a consequence of spin coating of the ZnO NC layers. Generally, this effect was less pronounced for the films prepared using $C_{\mathrm{ZnO}}=9.0$ and $28.0 \mathrm{mg} \mathrm{mL}^{-1}$.

The absorption coefficient $(\alpha)$ for the ZnO NC/MDMO-PPV multilayer films was assumed to be proportional to the overall volume fraction of MDMO-PPV present $\left(\alpha_{\mathrm{MDM}}\right)$ and the absorption coefficient of MDMO-PPV $\left(\alpha_{\text {MDM }}\right)$.

$$
\alpha=\phi_{\mathrm{MDM}} \alpha_{\mathrm{MDM}}
$$

The experimental $\alpha$ value $\left(\alpha_{\exp }\right)$ was determined from the gradient of plots of the absorbance maximum against film thickness (Fig. S6, ESI $\dagger$ ). The $\alpha_{\exp }$ values are shown in Fig. $4(\mathrm{c})$. A value of $\alpha_{\text {MDM }}=1.3 \times 10^{7} \mathrm{~m}^{-1}$ was estimated from the absorbance of the MDMO-PPV film (Fig. 4(a)) and its thickness $(10 \mathrm{~nm})$. The latter value is the same as that reported 

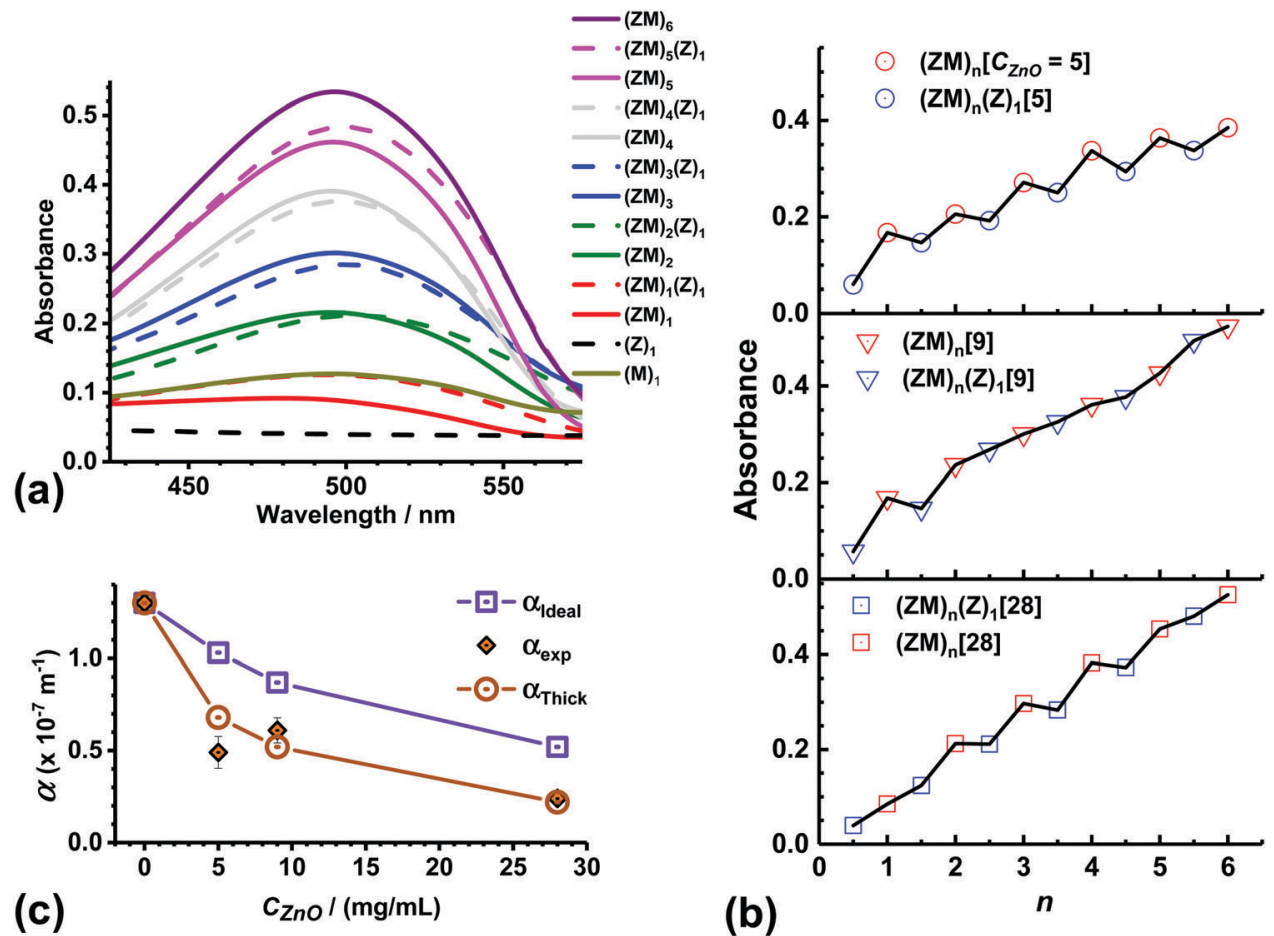

Fig. 4 (a) UV-visible spectra for ZnO NC/MDMO-PPV multilayer films prepared using $C_{Z n O}=28.0 \mathrm{mg} \mathrm{mL}^{-1}$. (b) Variation of absorbance measured at $505 \mathrm{~nm}$ with bilayer number for the films prepared using $C_{\mathrm{ZnO}}=5.0$ (top), 9.0 (middle) and 28.0 (bottom) mg mL ${ }^{-1}$. (c) Absorption coefficient for the films versus $C_{\text {Zno }}$ where $\alpha_{\text {exp }}, \alpha_{\text {Ideal }}$ and $\alpha_{\text {Thick }}$ were experimentally obtained or those determined using $\phi_{\text {MDM }}$ values calculated from eqn (2) and (3), respectively (see text).

in the literature. ${ }^{29}$ We calculated ideal absorption coefficients $\left(\alpha_{\text {Ideal }}\right)$ for the multilayer films using ideal $\phi_{\mathrm{MDM}}$ values $\left(\phi_{\mathrm{MDM} \text { (Ideal) }}\right)$ using the assumption that all of the ZnO NCs and MDMO-PPV used to spin coat the films was incorporated. The equation used was

$$
\phi_{\mathrm{MDM}(\mathrm{Ideal})}=\frac{1}{1+\left(\frac{c_{\mathrm{ZnO}} V_{\mathrm{Tot}(\mathrm{ZnO})} \rho_{\mathrm{MDM}}}{c_{\mathrm{MDM}} V_{\mathrm{Tot}(\mathrm{MDM})} \rho_{\mathrm{ZnO}}}\right)}
$$

where $C_{\mathrm{MDM}}, V_{\mathrm{Tot}(\mathrm{ZnO})}$ and $V_{\mathrm{Tot}(\mathrm{MDM})}$ are the MDMO-PPV solution concentration and the total volumes of the ZnO NC and MDM-PPV solutions used to spin coat each film layer, respectively. (The latter volumes were $50 \mu \mathrm{L}$.) The parameters $\rho_{\mathrm{MDM}}$ and $\rho_{\mathrm{ZnO}}$ are the densities of MDMO-PPV (5.61 $\left.\mathrm{g} \mathrm{mL}^{-141}\right)$ and $\mathrm{ZnO}\left(0.91 \mathrm{~g} \mathrm{~mL}^{-136}\right)$, respectively. The derivation of eqn (2) is given in the ESI. $\dagger$ The values for $\alpha_{\text {Ideal }}$ are plotted in Fig. 4(c) and it can be seen that in all cases $\alpha_{\text {Ideal }}>\alpha_{\text {exp }}$. This result implies that the experimental $\phi_{\text {MDM }}$ value was less than $\phi_{\text {MDM(Ideal). Presumably, some MDMO-PPV was }}$ removed during multilayer film construction. We also calculated $\alpha$ values $\left(\alpha_{\text {Thick }}\right)$ using eqn (1) and $\phi_{\text {MDM }}$ values estimated from the average thicknesses ( $\left.\phi_{\mathrm{MDM}(\text { Thick) }}\right)$ of the MDMO-PPV $\left(t_{\mathrm{MDM}}\right)$ and $\mathrm{ZnO}$ layers $\left(t_{\mathrm{ZnO}}\right)$ in the films using

$$
\phi_{\mathrm{MDM}(\text { Thick })}=\frac{t_{\mathrm{MDM}}}{t_{\mathrm{MDM}}+t_{\mathrm{ZnO}}}
$$

The average $t_{\mathrm{MDM}}$ and $t_{\mathrm{Zno}}$ values used in eqn (3) were taken from Fig. 1(c). Fig. 4(c) shows that the agreement between the $\alpha_{\text {Thick }}$ and $\alpha_{\exp }$ values is reasonably close. Hence, there was a good correlation between layer thickness and light absorption for the multilayer films. Thus, very good tuneability of light absorption within these ZnO NC/MDMO-PPV multilayer films can be achieved using either $n$ or $C_{\mathrm{ZnO}}$. We note that it became experimentally difficult to obtain good quality multilayer films when $n$ was increased to beyond six using the conditions employed in this study.

Photoluminescence (PL) spectra were also measured for the three ZnO NC/MDMO-PPV multilayer films. The spectra measured for the films prepared using $C_{\mathrm{ZnO}}=28.0 \mathrm{mg} \mathrm{mL}$ appear in Fig. 5(a) and those measured for the films prepared using 5.0 and $9.0 \mathrm{mg} \mathrm{mL}^{-1}$ are shown in Fig. S7 (ESI $\dagger$ ). The PL spectra are dominated by the MDMO-PPV signal with a maximum at 575 to $585 \mathrm{~nm}$. Surprisingly, there was a pronounced change in the wavelength of maximum intensity $\left(\lambda_{\max }\right)$ as $n$ increased. A pronounced zig-zag pattern was evident for the multilayer films prepared using $C_{\mathrm{ZnO}}=28.0 \mathrm{mg} \mathrm{mL}^{-1}$ (see Fig. 5(b), bottom). The $\lambda_{\text {max }}$ values for the MDMO-PPV layers (i.e., $(\mathrm{ZM})_{n}$ ) were shifted to the red after addition of the subsequent $\mathrm{ZnO}$ layers (i.e., $\left.(\mathrm{ZM})_{n}(\mathrm{Z})_{1}\right)$. However, the $\lambda_{\max }$ red-shift was less pronounced for the films prepared using $C_{\mathrm{ZnO}}=5.0$ and $9.0 \mathrm{mg} \mathrm{mL}^{-1}$. These differences in red-shift can be seen from Fig. 5(c) which shows the average redshift for the three multilayer films calculated using the data from Fig. 5(b).

The PL spectra for MDMO-PPV can become red-shifted due to aggregation. ${ }^{42}$ It follows that the wavelength shifts observed in Fig. 5(c) may be due to aggregation changes caused by the different solvents used to deposit the ZnO NC and MDMOPPV layers. Accordingly, it is proposed that $\mathrm{BuOH} / \mathrm{CHCl}_{3} / 1-\mathrm{PA}$ 

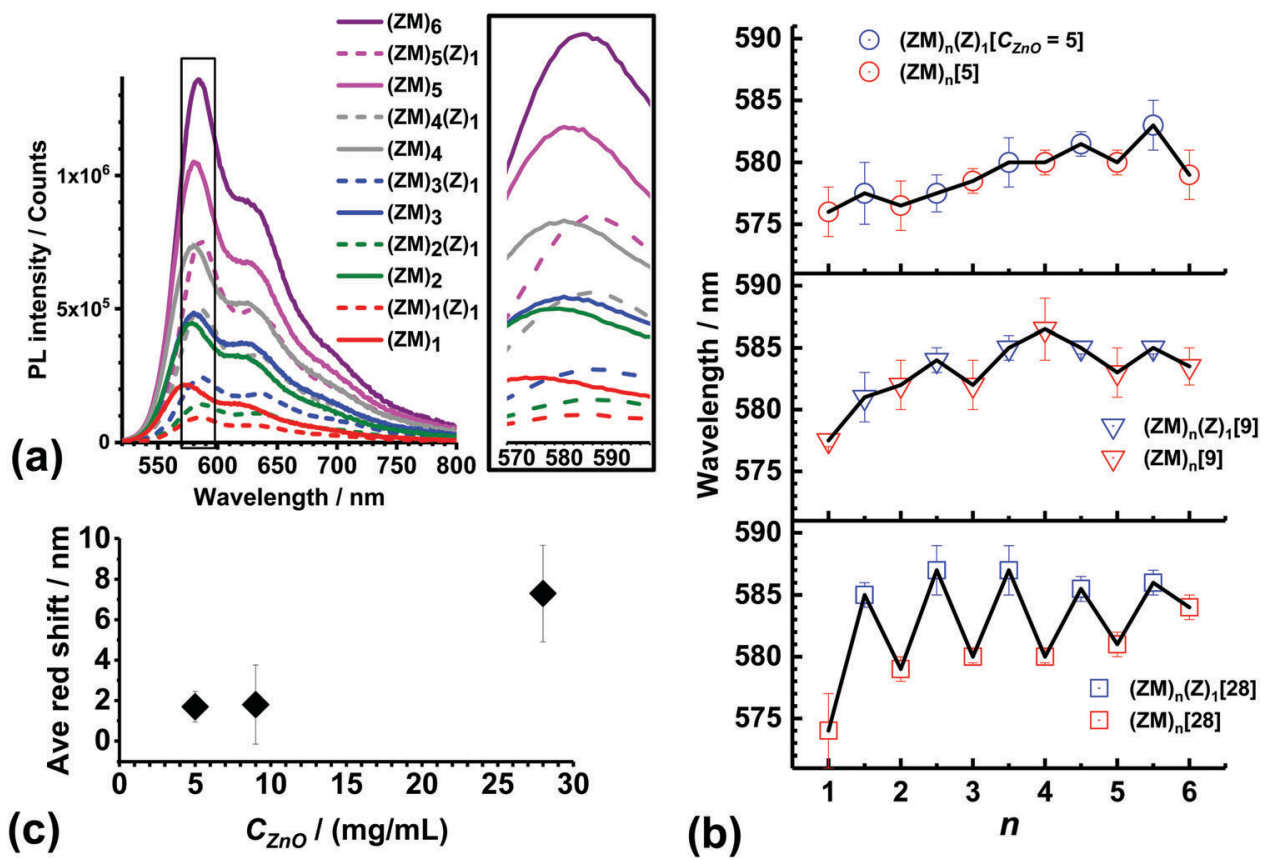

Fig. 5 (a) PL spectra for ZnO NC/MDMO-PPV multilayer films prepared using $C_{\mathrm{ZnO}}=28.0 \mathrm{mg} \mathrm{mL}^{-1}$. (b) Wavelength of maximum intensity $\left(\lambda_{\text {max }}\right)$ plotted against bilayer number for the three multilayer films. (c) Average red-shift for the respective $(Z M)_{n}(Z)_{1}$ film compared to the preceding $(Z M)_{n}$ film, i.e., $\lambda_{\text {Red }}=\lambda_{\max (n+0.5)}-\lambda_{\max (n)}$, where $n$ is an integer from 1 to 5 . Integer and fractional values of $n$ correspond to the $(Z M)_{n}$ films and $(Z M)_{n}(Z)_{1}$ films, respectively, as shown in Scheme 1.

(used to disperse the ZnO NCs) enhanced MDMO-PPV aggregation; whereas, CBZ (used to dissolve MDMO-PPV) decreased aggregation. The occurrence of a solvent-dependent PL spectrum for MDMO-PPV films was tested by recording spectra for MDMO-PPV deposited from $\mathrm{CBZ}$ before and after $\mathrm{CHCl}_{3}$ was spin coated onto the film (see Fig. S8, ESI $\dagger$ ). A red-shift of $4 \mathrm{~nm}$ was caused by the addition of $\mathrm{CHCl}_{3}$. This result supports our proposal that the solvent affected the extent of MDMO-PPV aggregation.

The measured PL intensities measured at $\lambda_{\max }$ are plotted against $n$ for the three multilayer films in Fig. 6(a). The PL intensities for the multilayer films with an MDMO-PPV top layer $\left((\mathrm{ZM})_{n}\right)$ were always greater than those for the subsequent film that contained a $\mathrm{ZnO} \mathrm{NC}$ top layer $\left((\mathrm{ZM})_{n(}(\mathrm{Z})_{1}\right)$ irrespective of the $C_{\mathrm{Zno}}$ value used. Partial loss of MDMO-PPV as a consequence of spin-coating of the subsequent $\mathrm{ZnO}$ layer may have contributed to these decreases in PL intensities. However, the latter effect was not dominant because the PL intensity decreases observed when ZnO NCs were spin coated (see Fig. 5(a) and Fig. S7, ESI $\dagger$ ) were much more pronounced than that observed by spin coating the same quantity of $\mathrm{CHCl}_{3}$ onto a MDMO-PPV film
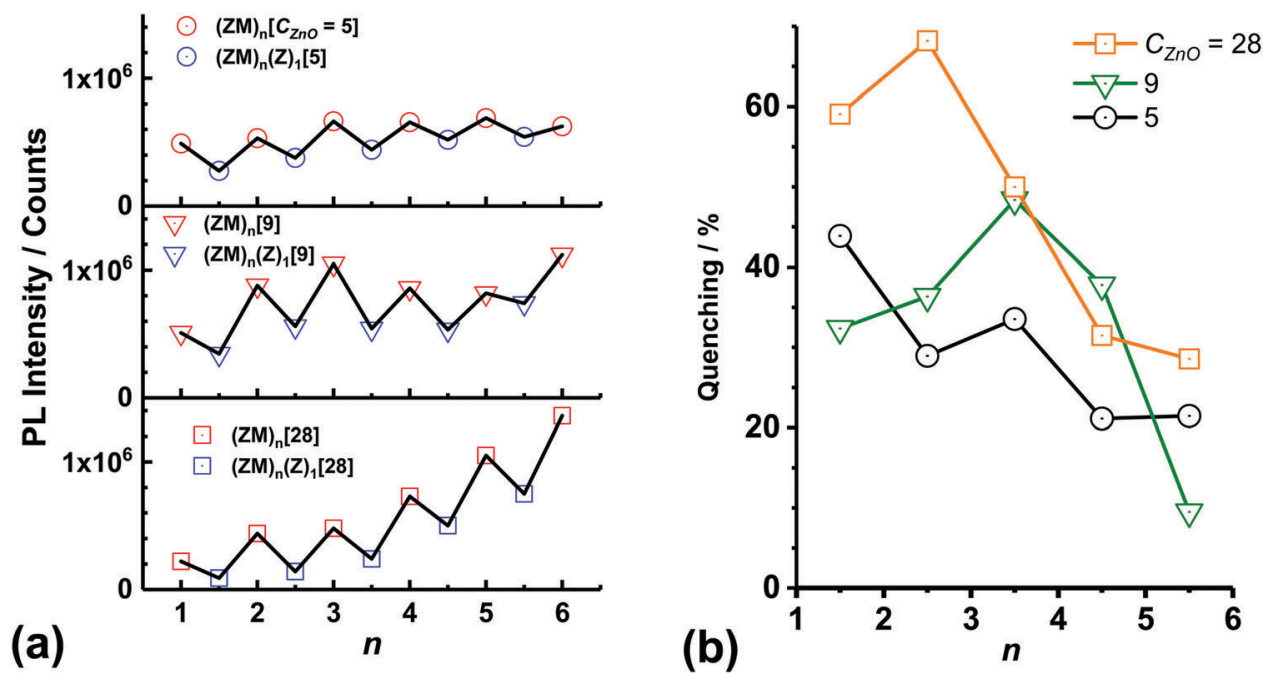

Fig. 6 (a) PL intensity measured at $\lambda_{\max }$ versus bilayer number for the three $\mathrm{ZnO}$ NC/MDMO-PPV multilayer films. (b) Variation of the calculated quenching efficiency $(Q)$ for the $(Z M)_{n}(Z)_{1}$ multilayer films. Values for $Q$ were calculated from the data shown in (a) and eqn (4). 
(see Fig. S8, ESI $\dagger$ ). Hence, it is concluded that quenching was primarily responsible for the observed decrease of the PL intensities when $\mathrm{ZnO}$ NC layers were spin coated onto the multilayer films. We note that the average layer thickness for the MDMO-PPV layers was $6.0 \pm 1.4 \mathrm{~nm}$ (see above). This value is less than the reported electron diffusion length. ${ }^{26}$ Consequently, excitons generated within the MDMO-PPV layers were likely to reach an MDMO-PPV/ZnO NC interface to enable quenching via electron transfer to a $\mathrm{NC}^{29}$

The quenching efficiency $(Q)$ for the multilayer films was calculated using the PL intensities shown in Fig. 6(a) and the following equation

$$
Q=100\left(\frac{I_{\max (n)}-I_{\max (n+0.5)}}{I_{\max (n)}}\right)
$$

where $I_{\max (n)}$ and $I_{\max (n+0.5)}$ are the PL intensities measured at $\lambda_{\text {max }}$ and $n$ is an integer from 1 to 5 . The $Q$ values are plotted in Fig. 6(b) and show that quenching was generally strongest for the multilayer films prepared with $n$ values less than or equal to 2.5. Quenching became weaker as $n$ increased beyond 2.5. This trend is attributed to summation of the non-quenched contributions to the total PL intensity within each additional MDMO-PPV layer deposited.

\section{Solar cells fabricated using ZnO NC/MDMO-PPV multilayer films}

Solar cells were constructed using the ZnO NC/MDMO-PPV multilayer films as the light harvesting component. It is understood that the use of one type of stacked acceptor/donor bilayer (or heterojunction) within a solar cell does not meet the energy level cascade requirements usually employed for high efficiency semiconducting NC/polymer solar cells. ${ }^{2,21,43}$ The aim of fabricating devices containing multilayer films (Fig. 7(a)) was to probe vertical transport of photo-generated charges. Devices were expected to fail through negligible short-circuit current densities $\left(J_{\mathrm{sc}}\right)$ if vertical charge transport was prevented. Representative $J-V$ curves measured for the devices are shown in Fig. 7(b). The measured figures of merit appear in Fig. 7(c) and Table S1 (ESI $\dagger$ ). A control bilayer device $\left((\mathrm{ZM})_{1}\right)$ was also prepared. The MDMO-PPV layer thickness for that device $(51 \mathrm{~nm})$ was approximately eight times that of the MDMOPPV layer thicknesses in the multilayer films. This relatively thick MDMO-PPV layer was required to achieve sufficient light absorption. The bilayer device PCE was $0.065 \pm 0.019 \%$ which is close to the value of $0.08 \%$ reported for a $\mathrm{ZnO} \mathrm{NC} / \mathrm{P} 3 \mathrm{HT}$ bilayer solar cell. ${ }^{44}$

The PCE values for the $(\mathrm{ZM})_{6}$ devices were low compared to bulk heterojunction NC/polymer solar cells ${ }^{21,29}$ due to the much lower $J_{\mathrm{sc}}$ values for the present devices. A relatively low $J_{\mathrm{sc}}$ value is consistent with the limited area of the ZnO NC/MDMOPPV interface in a planar film. It can be seen from the data shown in Fig. $7(\mathrm{c})$ that the $(\mathrm{ZM})_{6}$ devices prepared using $C_{\mathrm{Zno}}=$ 9.0-18.0 $\mathrm{mg} \mathrm{mL}^{-1}$ had figures of merit that were similar to those for the bilayer device. The average $V_{\mathrm{oc}}$ value for the $(\mathrm{ZM})_{6}$ devices prepared using $C_{\mathrm{ZnO}}=14.0 \mathrm{mg} \mathrm{mL}^{-1}$ was $796 \pm 11 \mathrm{mV}$ which is significantly higher than that measured for the bilayer devices $(686 \pm 88 \mathrm{mV})$. Interestingly, the former $V_{\mathrm{oc}}$ is one of the highest reported for $\mathrm{ZnO} / \mathrm{MDMO}-\mathrm{PPV}$ solar cells. ${ }^{43}$ The relatively good performance of the multilayer cells is attributed to vertical pathways for holes and electrons that penetrated the ZnO NC and MDMO-PPV layers, respectively. In contrast it was (a)

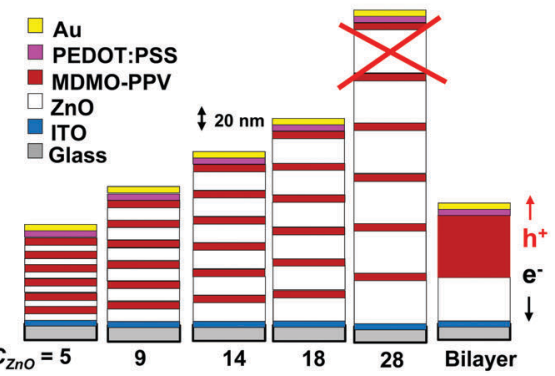

(b)

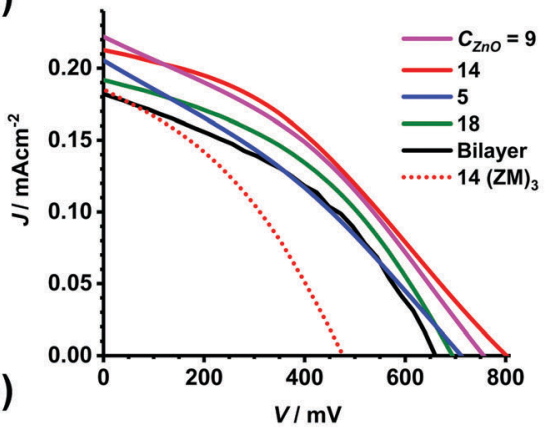

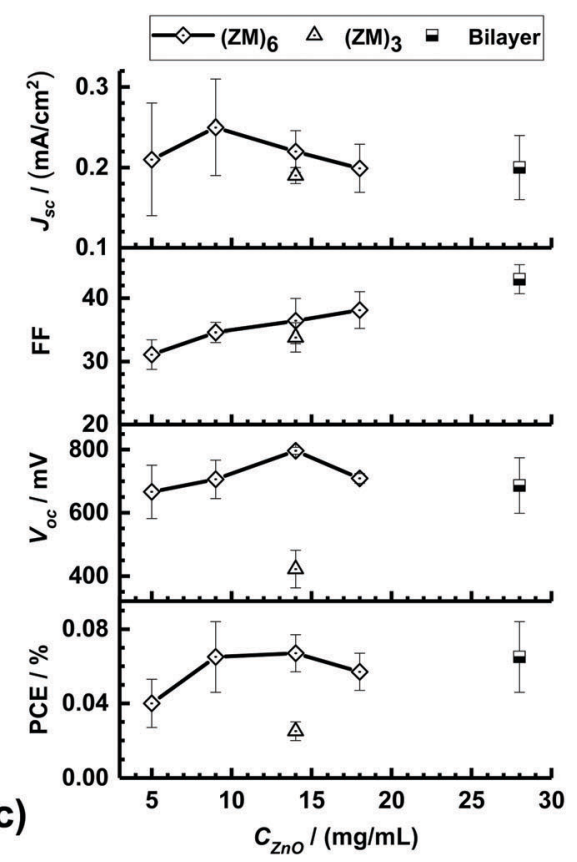

Fig. 7 (a) Depiction of fabricated device geometries showing the differences of the ZnO NC layer thicknesses. The $(Z M)_{6}$ devices prepared using $C_{Z n O}=28.0 \mathrm{mg} \mathrm{mL}^{-1}$ did not provide reliable performance data. The ITO, PEDOT:PSS and Au layers are not drawn to scale. (b) Representative $J-V$ curves for the $(Z M)_{6}$ devices and a control $(Z M)_{1}$ bilayer device. $\mathrm{A}(\mathrm{ZM})_{3}$ device was also prepared using $C_{\mathrm{ZnO}}=14.0 \mathrm{mg} \mathrm{mL}^{-1}$ (see text). The $C_{\mathrm{Zno}}$ values (mg mL ${ }^{-1}$ ) are shown in the legend. (c) Measured figures of merit plotted as a function of $C_{Z n O}$. 

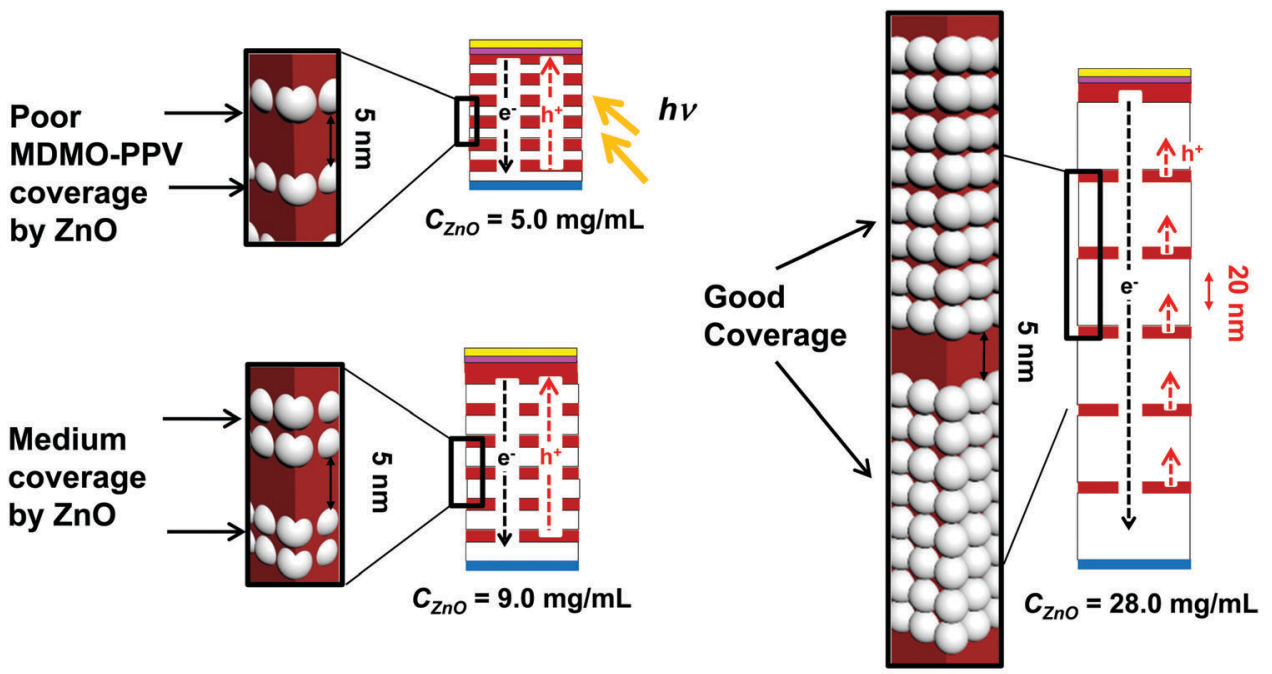

Fig. 8 Depiction of the proposed morphologies for ZnO NC/MDMO-PPV multilayer films. The concentration of MDMO-PPV within the ZnO NC layers is considered to be negligible for the film prepared using $C_{Z n O}=28.0 \mathrm{mg} \mathrm{mL}^{-1}$. The coverage of the MDMO-PPV layers by the ZnO NC layers increased with increasing $C_{\mathrm{ZnO}}$. There were vertical charge transport pathways for holes and electrons for the films prepared using $C_{\mathrm{ZnO}}=5.0$ and $9.0 \mathrm{mg} \mathrm{mL}^{-1}$. However, these pathways for holes were tortuous and less effective for the films prepared using $C_{\mathrm{ZnO}}=28.0 \mathrm{mg} \mathrm{mL}^{-1}$. Only the MDMO-PPV and ZnO NC layers and components are drawn to scale.

not possible to fabricate reliable solar cells containing multilayer films prepared using $C_{\mathrm{ZnO}}=28.0 \mathrm{mg} \mathrm{mL}^{-1}$. The relatively thick ZnO NC layers for those multilayer films (layer thickness = $32 \mathrm{~nm}$ ) most likely contained less MDMO-PPV based on the CA results (see Fig. 3(b)). Hence, those multilayer films had fewer and more tortuous vertical hole transport pathways that spanned the whole $\mathrm{ZnO}$ NC layer thickness.

$(\mathrm{ZM})_{3}$ devices were prepared using $C_{\mathrm{ZnO}}=14.0 \mathrm{mg} \mathrm{mL}^{-1}$ in order to assess the effect of the number of bilayers on performance. The data measured are shown in Fig. 7(b) and (c) as well as Table S1 $(\mathrm{ESI}+)^{\dagger}$. The average PCE for the $(\mathrm{ZM})_{3}$ devices was $0.025 \pm 0.005 \%$ which is $37 \%$ of the value for $(\mathrm{ZM})_{6}$. Closer examination of the data showed that the average $J_{\mathrm{sc}}$ and $V_{\mathrm{oc}}$ values for the $(\mathrm{ZM})_{3}$ devices were, respectively, $83 \%$ and $53 \%$ of the average values for the $(\mathrm{ZM})_{6}$ devices prepared using $C_{\mathrm{ZnO}}=14.0 \mathrm{mg} \mathrm{mL} \mathrm{m}^{-1}$. The decrease for $J_{\mathrm{sc}}$ was statistically significant ( $p<0.01$ from a Student's $t$-test) and is attributed to less light being absorbed by a $(\mathrm{ZM})_{3}$ film in accordance with the data shown in Fig. 4(b) for comparable films. The decrease in $V_{\mathrm{oc}}$ is primarily attributed to the decreased shunt resistance $\left(R_{\mathrm{sh}}\right)$ for the $(\mathrm{ZM})_{3}$ devices. The average $R_{\mathrm{sh}}$ values for the $(\mathrm{ZM})_{6}$ and $(\mathrm{ZM})_{3}$ devices were measured as $12.8 \pm 2.5 \mathrm{k} \Omega \mathrm{cm}^{2}$ and $4.7 \pm 1.6 \mathrm{k} \Omega \mathrm{cm}^{2}$, respectively. A small $R_{\mathrm{sh}}$ decreases the current flowing through the solar cell and decreases $V_{\mathrm{oc}}{ }^{45}$ We conclude that the $(\mathrm{ZM})_{6}$ multilayer devices gave the best PCE because of the greater light absorption and a higher $R_{\mathrm{sh}}$.

\section{Proposed morphology of ZnO NC/MDMO-PPV multilayer films}

We propose a model in Fig. 8 for the morphologies of the $\mathrm{ZnO}$ NC/MDMO-PPV multilayer films based on all the data. The proposed morphologies contain $\mathrm{ZnO} \mathrm{NC}$ layers that equal $\sim 1$,
2 and $8 \mathrm{NC}$ monolayers when $C_{\mathrm{ZnO}}=5.0,9.0$ and $28.0 \mathrm{mg} \mathrm{mL}^{-1}$. Each of the NC layers is separated by a MDMO-PPV layer which is similar to the diameter of a MDMO-PPV globule. The coverage of the MDMO-PPV layers by the ZnO NC layers increased with increasing $C_{\mathrm{Zno}}$ and was effectively complete for the multilayer film prepared using $C_{\mathrm{ZnO}}=28.0 \mathrm{mg} \mathrm{mL}{ }^{-1}$. We propose that there were numerous vertical percolated charge transport pathways for holes and electrons through the $\mathrm{ZnO} \mathrm{NC}$ and MDMO-PPV layers, respectively, of the multilayer films prepared using $C_{\mathrm{ZnO}}=5.0$ and $9.0 \mathrm{mg} \mathrm{mL}^{-1}$. In contrast the film prepared using $C_{\mathrm{ZnO}}=28.0 \mathrm{mg} \mathrm{mL}^{-1}$ did not have significant MDMO-PPV connectivity because the ZnO NC layers were too thick. Thus, the hole transport pathway was very inefficient in that film.

\section{Conclusions}

In this study we have investigated the morphologies and optoelectronic properties of sequentially spin-coated $\mathrm{ZnO} \mathrm{NC/}$ MDMO-PPV multilayer films. The ZnO NC layers had the same average thicknesses as those deposited on ITO glass. In contrast the average thickness for the MDMO-PPV layers was less than that deposited on ITO, which was probably due to some removal of some of the polymer by $\mathrm{CHCl}_{3}$ used for $\mathrm{ZnO} \mathrm{NC}$ layer deposition. The CA data provided evidence that the coverage of the MDMO-PPV layers by the ZnO NC layers increased as the $C_{\mathrm{ZnO}}$ increased. The coverage was complete when $C_{\mathrm{ZnO}}=$ $28.0 \mathrm{mg} \mathrm{mL}{ }^{-1}$. Light absorption by the multilayer films increased linearly with the number of MDMO-PPV layers deposited. The film absorption coefficient was tuneable using either layer thickness or $C_{\mathrm{Zno}}$. The PL data showed an unexpected $5 \mathrm{~nm}$ red-shift of the PL 
maximum for MDMO-PPV. Substantial and reversible PL quenching also occurred. The $J-V$ data showed that the $(\mathrm{ZM})_{6}$ devices performed well compared to a conventional $(\mathrm{ZM})_{1}$ bilayer device. The maximum $V_{\mathrm{oc}}$ values obtained for the $(\mathrm{ZM})_{6}$ device prepared using $C_{\mathrm{ZnO}}=14.0 \mathrm{mg} \mathrm{L}^{-1}$ is amongst the highest reported for $\mathrm{ZnO}$ NC/MDMO-PPV solar cells. The highly tuneable light absorption as well as the vertical charge transport for the ZnO NC/MDMO-PPV multilayer films studied here should also apply to other types of QD/polymer multilayer films and devices.

\section{Conflicts of interest}

There are no conflicts of interest to declare.

\section{Acknowledgements}

The authors thank the staff in the EM Core Facility in the Faculty of Biology, Medicine and Health for their assistance, and the Wellcome Trust for equipment grant support to the EM Core Facility. We also gratefully acknowledge funding from the EPSRC (Grant K009710/1).

\section{References}

1 J. Yan and B. R. Saunders, RSC Adv., 2014, 4, 43286-43314. 2 S. Ren, L.-Y. Chang, S.-K. Lim, J. Zhao, M. Smith, N. Zhao, V. Bulović, M. Bawendi and S. Gradečak, Nano Lett., 2011, 11, 3998-4002.

3 W. J. Beek, M. M. Wienk and R. A. Janssen, Adv. Funct. Mater., 2006, 8, 1112-1116.

4 S. D. Oosterhout, M. M. Wienk, M. Al-Hashimi, M. Heeney and R. A. J. Janssen, J. Phys. Chem. C, 2011, 115, 18901-18908.

5 H. J. Snaith, A. Stavrinadis, P. Docampo and A. A. R. Watt, Sol. Energy, 2011, 85, 1283-1290.

6 N. Tulsiram, C. Kerr and J. I. L. Chen, J. Phys. Chem. C, 2017, 121, 26987-26996.

7 K. Prashanthan, T. Thivakarasarma, P. Ravirajan, M. Planells, N. Robertson and J. Nelson, J. Mater. Chem. C, 2017, 5, 11758-11762.

8 M. Eyer, J. Frisch, S. Sadofev, N. Koch, E. J. W. ListKratochvil and S. Blumstengel, J. Phys. Chem. C, 2017, 121, 21955-21961.

9 M. T. Khan and A. Almohammedi, J. Appl. Phys., 2017, 122, 075502.

10 S. Dayal, N. Kopidakis, D. C. Olson, D. S. Ginley and G. Rumbles, Nano Lett., 2010, 10, 239-242.

11 W. Chen, M. P. Nikiforov and S. B. Darling, Energy Environ. Sci., 2012, 5, 8045-8074.

12 M. Wright and A. Uddin, Sol. Energy Mater. Sol. Cells, 2012, 107, 87-111.

13 U. Jabeen, T. Adhikari, S. M. Shah, D. Pathak and J.-M. Nunzi, Opt. Mater., 2017, 73, 754-762.

14 S. A. McDonald, G. Konstantatos, S. Zhang, P. W. Cyr, E. J. D. Klem, L. Levina and E. H. Sargent, Nat. Mater., 2005, 4, 138.
15 G. Gou, G. Dai, X. Wang, Y. Chen, C. Qian, L. Kong, J. Sun and J. Yang, Appl. Phys. A: Mater. Sci. Process., 2017, 123, 731.

16 X. Dai, Z. Zhang, Y. Jin, Y. Niu, H. Cao, X. Liang, L. Chen, J. Wang and X. Peng, Nature, 2014, 515, 96.

17 S. D. Oosterhout, M. M. Wienk, S. S. van Bavel, R. Thiedmann, L. Jan Anton Koster, J. Gilot, J. Loos, V. Schmidt and R. A. J. Janssen., Nat. Mater., 2009, 8, 818.

18 B. R. Saunders and M. L. Turner, Adv. Colloid Interface Sci., 2008, 138, 1-23.

19 S. D. Dimitrov and J. R. Durrant, Chem. Mater., 2014, 26, 616-630.

20 J. Zhao, Y. Li, G. Yang, K. Jiang, H. Lin, H. Ade, W. Ma and H. Yan, Nat. Energy, 2016, 1, 15027.

21 Z. Liu, Y. Sun, J. Yuan, H. Wei, X. Huang, L. Han, W. Wang, H. Wang and W. Ma, Adv. Mater., 2013, 25, 5772-5778.

22 E. A. Meulenkamp, J. Phys. Chem. B, 1998, 102, 5566-5572.

23 M. R. Waugh, G. Hyett and I. P. Parkin, Chem. Vap. Deposition, 2008, 14, 366-372.

24 R. M. Hewlett and M. A. McLachlan, Adv. Mater., 2016, 28, 3893-3921.

25 P. Zhang, J. Wu, T. Zhang, Y. Wang, D. Liu, H. Chen, L. Ji, C. Liu, W. Ahmad, Z. D. Chen and S. Li, Adv. Mater., 2018, 30, 1703737.

26 P. Ravirajan, A. M. Peiro, M. K. Nazeeruddin, M. Graetzel, D. D. Bradley, J. R. Durrant and J. Nelson, J. Phys. Chem. B, 2006, 110, 7635-7639.

27 J. Yan, Q. Lian, M. Z. Mokhtar, A. H. Milani, E. Whittaker, B. Hamilton, P. O'Brien, N. T. Nguyen and B. R. Saunders, Phys. Chem. Chem. Phys., 2017, 19, 27081-27089.

28 G. P. Bartholomew and A. J. Heeger, Adv. Funct. Mater., 2005, 15, 677-682.

29 W. J. Beek, M. M. Wienk, M. Kemerink, X. Yang and R. A. Janssen, J. Phys. Chem. B, 2005, 109, 9505-9516.

30 S. B. Dkhil, D. Duché, M. Gaceur, A. K. Thakur, F. B. Aboura, L. Escoubas, J.-J. Simon, A. Guerrero, J. Bisquert, G. GarciaBelmonte, Q. Bao, M. Fahlman, C. Videlot-Ackermann, O. Margeat and J. Ackermann, Adv. Energy Mater., 2014, 4, 1400805.

31 H. L. Gao, X. W. Zhang, J. H. Meng, Z. G. Yin, L. Q. Zhang, J. L. Wu and X. Liu, J. Mater. Chem. A, 2015, 3, 3719-3725.

32 A. P. Wanninayake, B. C. Church and N. Abu-Zahra, AIMS Mater. Sci., 2016, 3, 927-937.

33 S. Woo, W. Hyun Kim, H. Kim, Y. Yi, H.-K. Lyu and Y. Kim, Adv. Energy Mater., 2014, 4, 1301692.

34 J. You, C. C. Chen, L. Dou, S. Murase, H. S. Duan, S. A. Hawks, T. Xu, H. J. Son, L. Yu, G. Li and Y. Yang, Adv. Mater., 2012, 24, 5267-5272.

35 D. H. Everett, Basic Principles of Colloid Science, RSC, Cambridge, 1988.

36 C. W. T. Bulle-Lieuwma, W. J. H. van Gennip, J. K. J. van Duren, P. Jonkheijm, R. A. J. Janssen and J. W. Niemantsverdriet, Appl. Surf. Sci., 2003, 203-204, 547-550.

37 P. Cooreman, R. Thoelen, J. Manca, M. vandeVen, V. Vermeeren, L. Michiels, M. Ameloot and P. Wagner, Biosens. Bioelectron., 2005, 20, 2151-2156.

38 L.-T. Lee, T. Ube, H. Aoki and S. Ito, Polymer, 2011, 52, 5897-5903. 
39 R.-D. Sun, A. Nakajima, A. Fujishima, T. Watanabe and K. Hashimoto, J. Phys. Chem. B, 2001, 105, 1984-1990.

40 S. Wu, Q. Tai and F. Yan, J. Phys. Chem. C, 2010, 114, 6197-6200.

41 R. C. Weast, CRC handbook of chemistry and physics, CRC Press, Florida, 65th edn, 1985.

42 D. Jarzab, M. Lu, H. T. Nicolai, P. W. M. Blom and M. A. Loi, Soft Matter, 2011, 7, 1702-1707.
43 W. J. Beek, M. M. Wienk and R. A. J. Janssen, Adv. Mater., 2004, 16, 1009-1013.

44 S. R. Ferreira, R. J. Davis, Y.-j. Lee, P. Lu and J. W. P. Hsu, Org. Electron., 2011, 12, 1258-1263.

45 G. Jin, Z. Chen, C. Dong, Z. Cheng, X. Du, Q. Zeng, F. Liu, H. Sun, H. Zhang and B. Yang, ACS Appl. Mater. Interfaces, 2016, 8, 7101-7110. 